\title{
Dendritic Cell Tumor Peptide Vaccine
}

National Cancer Institute

\section{Source}

National Cancer Institute. Dendritic Cell Tumor Peptide Vaccine. NCI Thesaurus. Code C1987.

A vaccine composed of dendritic cells pulsed with peptide epitopes that stimulate cytotoxic T lymphocyte anti-tumor activity. ( $\mathrm{NCl})$ 